\title{
Os planos narrativos em "Super Flumina Babylonis""
}

RESUMO: No conto "Super Flumina Babylonis", constante da obra Antigas e novas andanças do demónio (1981), Jorge de Sena recria, pela voz de um narrador heterodiegético, o processo de composição das redondilhas "Sobre os rios que vão", também conhecidas como "Babel e Sião", de Luís Vaz de Camões. Observamos que o conto é constituído por dois grandes blocos: o do "diálogo" entre Camões e a mãe e o da narração propriamente dita, o qual, por seu turno, divide-se em dois planos - o exterior, correspondente ao mundo concreto, da realidade física, e o interior, correspondente ao mundo psicológico da personagem. Tendo isso em vista, neste trabalho, objetivamos analisar como se estruturam esses dois planos, a fim de estabelecer relação entre o conto de Sena e o poema de Camões.

PALAVRAS-CHAVE: Planos narrativos. "Super Flumina Babylonis". Jorge de Sena. Literatura Portuguesa.

\section{NARRATIVE LEVELS IN “SUPER FLUMINA BABYLONIS”}

ABSTRACT: In the short story "Super Flumina Babylonis", through the voice of a heterodiegetic narrator, Jorge de Sena recreates the writing process of the poem "Sobre os rios que vão", also known as "Babel e Sião", written by the Portuguese poet Luís Vaz de Camões. We observed that the narrative consists in two segments: the "dialogue" between Camões and his mother, and the narration itself, which is divided into two levels - the exterior one, that corresponds to the concrete world, of physical reality, and the interior one, that corresponds to the psychological world of the character. In this work, we aim to analyse how both levels are structured, in order to establish the connection between Sena's short story and Camões' poem.

KEYWORDS: Narrative levels. "Super Flumina Babylonis". Jorge de Sena. Portuguese Literature.

Embora fosse engenheiro civil por formação, foi nas Letras, como ficcionista, dramaturgo, tradutor, ensaísta, professor universitário e crítico literário, que Jorge de Sena encontrou o êxito profissional. Entre a docência e a escrita, dedicou-se ao estudo e à crítica da obra de Luís de Camões, de quem também se serviu como personagem ficcional. Em "Super Flumina Babylonis", conto escrito em 1964, durante seu exílio voluntário no Brasil, e publicado originalmente em 1966, na coletânea de contos Novas andanças do demónio ${ }^{3}$, o escritor recria ficcionalmente a composição das redondilhas "Sobre os rios que vão", supostamente nos últimos anos de vida de Camões, já alojado com a mãe na miséria, após sua volta das Índias e a publicação d'Os Lusíadas. As redondilhas, também conhecidas como "Babel e Sião", são inspiradas no salmo 136 da Bíblia, que nomeia não só o poema de Camões como também o

\footnotetext{
${ }^{1}$ O presente trabalho foi realizado com apoio da Coordenação de Aperfeiçoamento de Pessoal de Nível Superior - Brasil (CAPES) - Código de Financiamento 001.

${ }^{2}$ Mestranda em Letras - Estudos Literários - Universidade Federal de Santa Maria (UFSM).

3 Aqui utilizamos a segunda edição de Antigas e novas andanças do demónio (1981), que reúne os contos inicialmente publicados em Antigas andanças do demónio (1960) e Novas andanças do demónio (1966).

4 Optamos pela versão "Sobre os rios que vão" por ser ela a forma empregada na primeira edição, de 1595, das Rimas de Camões (SENA, 1980, p. 127).
} 
conto de Sena.

É importante ressaltar que as personagens jamais são nomeadas ao longo do conto. Para Carla Ribeiro (2008, p. 5), isso provavelmente se deve ao fato de que "não é o indivíduo Camões que está em questão, mas sim o grande poeta e sua obra, naquilo que permanece como intemporal e universal”. Isso porque, segundo Jorge de Sena (1980, p. 288, grifo do autor), no ensaio "Camões: o poeta lírico", ele é a "obcessiva persona que [...] criou nos seus próprios escritos", e, se pouco sabemos dele, "biograficamente falando, tudo sabemos da sua persona poética, já que não muitos poetas [...] transformaram a sua própria experiência e pensamento numa tal reveladora obra de arte, como a poesia de Camões é” (SENA, 1980, p. 290). Provavelmente seja a isso que o autor alude, no Prefácio a Novas andanças do demónio, quando diz predominar um certo "realismo fantástico ou historicismo imaginoso" nos contos que integram o volume (SENA, 1981, p. 220), uma vez que o Camões de "Super Flumina Babylonis" é muito mais um exercício imaginativo, baseado em sua persona poética e naquilo que ficou impresso em sua obra, do que uma tentativa de representação verdadeira do homem que realmente existiu. A despeito de Jorge de Sena incluir na narrativa dados biográficos verídicos sobre Camões (que são mencionados nas notas do conto), é o seu profundo conhecimento da obra e do poeta que tornam sua personagem tão verossímil, como, talvez, só ele seria capaz de compreender e de representar.

No que concerne à estrutura, Ribeiro (2008, p. 7-8) sugere que "Super Flumina Babylonis" é composto por duas "sequências": de um lado, as "reflexões interiores de Camões" e, de outro, "o longo monólogo de sua mãe". Entretanto, propomos aqui a leitura do conto a partir, também, de dois grandes segmentos, mas sendo eles o do "diálogo" entre Camões e a mãe e o da narração propriamente dita, o qual, por seu turno, divide-se em dois planos - o exterior, correspondente ao mundo concreto, da realidade física, e o interior, correspondente ao mundo psicológico da personagem. Interessa assinalar que a mãe funciona como "uma espécie de encarnação do real contraposta ao estado de devaneio em que o poeta está mergulhado" e que "a verdadeira acção, o que verdadeiramente acontece, está no que o poeta pensa e não no que ele ou sua mãe possam dizer" (HATHERLY, 1999, p. 29). Ainda cabe ressaltar que os parágrafos narrativos apresentam construção paralelística, uma vez que se constituem pela associação dos dois planos, dispostos de forma que os elementos referentes ao plano exterior ora provoquem, ora interrompam aqueles referentes ao plano interior. Tendo isso em vista, objetivamos analisar como esses dois planos se constroem, a fim de estabelecer relação entre o conto de Sena e o poema de Camões.

No conto, a ação transcorre em um curto período: do final da tarde, quando Camões 
retorna a casa de seu encontro habitual com os frades de São Domingos, à noite, quando inicia a composição do poema. Subindo a escada que dá acesso ao lugar onde mora, a personagem entrega-se a divagações. Ao entrar em casa, percebe a ausência da mãe. $O$ silêncio e a solidão motivam o poeta a continuar os devaneios. Em seguida, a mãe retorna e inicia um extenso diálogo - quase monólogo, uma vez que o filho só toma a palavra para corrigi-la e contrariá-la -, no qual discorre sobre os acontecimentos do dia, dentre os quais a visita do criado de Rui Dias, fidalgo que encomendara a Camões a tradução em verso dos "Salmos del-rei David". Com a chegada da noite, ao buscar o fogo para acender a candeia, a mãe o deixa novamente sozinho, possibilitando que ele, mais uma vez, ponha-se a devanear. Ao voltar portando a candeia, ela torna a mencionar Rui Dias e logo depois se vai deitar. Só, o poeta inicia a composição das redondilhas.

No parágrafo que abre a narrativa, o narrador apresenta o espaço em que se desenvolve a ação, no momento em que a personagem sobe a escada que dá acesso à casa:

A ascensão da estreita escada escura, e tão a pino, com os degraus muito altos e cambaios, era, sempre que voltava a casa, uma tortura. À força de equilíbrios, meio encostado à parede, cuja cal já se esvaíra havia muito e até nas suas costas, e apoiando em viés uma das muletas no extremo oposto do degrau de cima, ia subindo cuidadosamente, num resfolegar de raiva pela lentidão. (SENA, 1981, p. 155) ${ }^{5}$

A apresentação do espaço instaura uma atmosfera de decadência, visto que a escada é “estreita", "escura” e elevada; os degraus, "altos e cambaios”, e a parede parece descascada. Essa degradação estende-se à personagem, que utiliza muletas para se apoiar e subir a escada e ainda precisa se encostar à parede a fim de não se desequilibrar. A subida exige tanto esforço físico, a ponto de se constituir uma tortura, perceptível pelo modo como tal ação se realiza, "num resfolegar de raiva pela lentidão". A degradação, mais do que abranger apenas as condições físicas da personagem, envolve-a moralmente. Um grande poeta, que, agora, na velhice, encontra-se na penúria, desterrado em sua própria pátria e "destituído até da alegria de fazer versos" (p. 157). É interessante destacar que, conforme Teresa Cristina Cerdeira da Silva (1999, p. 306), estamos diante de um poeta para quem “a vida que conta é só a do passado, já que a do futuro lhe parece definitivamente roubada. Marcado pela dor, pela doença, pela ausência do canto, esse poeta da ficção pode, de certo modo, caracterizar-se metaforicamente como aquele que atravessa o tempo de Babilônia". Além disso, ela destaca que

${ }^{5}$ A partir daqui, todas as citações do conto serão referenciadas apenas pelo número da(s) página(s). 
o tempo do sacrifício está inscrito, para além do nível semântico de palavras como tortura, resfolegar, raiva, tristezas, poço insólito em sua profundeza negra, também numa camada fônica quase abusivamente trabalhada por Sena, a ponto de conferir ao conto uma estatura de poema em prosa. (SILVA, 1999, p. 306)

Já de início se estabelece um contraste, que perdura até o fim do conto, entre o que Camões é e o que foi. Agora, abandonado, "alquebrado e impotente" (p. 158), sem "espírito nem contentamento para nada" (p. 166); antes, um grande poeta, "mancebo farto e namorado, querido e estimado, e cheio de muitos favores e mercês de amigos e damas, com que o calor poético se aumentava" (p. 166). A comparação se verifica, também, na distribuição dos planos narrativos, dado que o plano exterior compreende acontecimentos reais imediatos, presentes, os quais, através do que a personagem vê e ouve - tanto do ambiente ao redor, quanto das falas da mãe -, deflagram o plano interior. Esse plano, por sua vez, abrange devaneios e lembranças de acontecimentos reais do passado. Em um dos planos, a personagem observa sua vida, no mundo concreto que a rodeia, por meio dos acontecimentos que a envolvem. No outro, contempla seu mundo psicológico, narrado em discurso indireto livre, permeado por lembranças e devaneios - sobretudo acerca da criação poética -, que se dão pela associação de pensamentos.

Logo no começo do conto, é a subida atribulada o elemento deflagrador das digressões, que ocorrem durante todo o percurso até a porta da casa. Nesse primeiro momento, é a sensação do tato que atrela a personagem ao mundo concreto e que a introduz em seu mundo psicológico, por meio do desconforto físico, que faz com que pense nas tentativas da mãe de estabelecer diálogo, a fim de evitar que o filho se entregasse a "solitários pensamentos" (p. 155). Camões, no entanto, não teme os pensamentos, mas os "vazios cada vez maiores" (p. 156) que se fazem entre eles. Ele não se pode deixar distrair pelas palavras da mãe, pois isso provoca a abertura de "um vácuo tenebroso, um vórtice sombrio", em que flutuam "farrapos de versos e de coisas vistas" (p. 156), lembranças do que foi criado e vivido. Mais ao fundo desse "fio interrompido das ideias", que deslizam como um "rio revolto", encontra-se "uma pequenina porta, ou um vidro posto sobre estranhas águas" em que nadam "esquisitos seres" (p. 156), representando pensamentos obscuros e ideias nefastas. A fim de afugentar essa visão, "sempre a mesma” (p. 156), a personagem precisa de cerrar fortemente os olhos.

Da associação dos pensamentos, emergem o sentimento de desterro do poeta e a reflexão sobre o fazer poético: "Os seus versos, agora, haviam-no abandonado. Haviam-se desfeito, como açúcar, no rio ininterrupto do pensamento, aonde antigamente flutuavam de súbito, como pedaços de ardente gelo, que um a um se atrelavam para dar um poema" (p. 157, grifos nossos). É interessante notar, no fragmento citado, o uso do oxímoro, "pedaços de ardente gelo", que lembra as imagens paradoxais na 
poesia camoniana. Com isso, reitera-se o contraste entre o seu momento atual, de degradação física, material e moral, já "destituído até da alegria de fazer versos" (p. 157), e o seu período de profícua produção poética. O poeta, então, apresenta-se como um ordenador do mundo, uma vez que "as coisas se arrumavam por sua vontade, [...] a ordem delas e do Mundo era um desconcerto que ele organizava mentalmente" (p. 156) e que escrevera, em suma, "para que vissem como tudo, na vida, tinha um sentido exacto que só ele era capaz de achar, uma arquitectura que não teria tido sem ele” (p. 157), numa alusão ao desconcerto do mundo, um motivo recorrente em sua poesia e sentimento constante na vida da personagem. A respeito dessa característica do Camões-poeta, incorporada com mestria ao Camõespersonagem, Jorge de Sena, em "Camões: o poeta lírico", declara que

Camões é, na mais existencial maneira, um poeta filosófico, profundamente preocupado com encontrar um sentido para um mundo que parecia, no ocaso da Renascença, mais e mais sem sentido - um sentido que ele atinge estruturalmente impondo a ordem e o equilíbrio dos seus poemas à desordem deste mundo. (SENA, 1980, p. 291, grifo do autor)

Do momento em que a personagem entra em casa até o momento em que se senta, há uma suspensão dos devaneios e um retorno ao mundo concreto: "Empurrou a porta, e entrou. Contra o costume, a mãe não lhe apareceu, nem ele sentiu na casa ruído algum. Fechou a porta, foi até à mesa, e sentou-se na cadeira, encostando as muletas" (p. 157). Os devaneios desenrolam-se em poucos segundos, visto que o plano exterior deste parágrafo claramente justapõe-se ao do primeiro. Assim como na abertura do conto, as divagações da personagem são motivadas pelo desconforto físico e pelo silêncio no ambiente. Ao constatar a ausência da mãe, Camões permite-se "sentar-se ajeitando as partes inchadas e doloridas" (p. 157), ato que habitualmente realiza envergonhado diante dela, pois a velhinha horroriza-se "com a monstruosidade dos castigos reservados a quem se entrega aos pecados da carne" (p. 157). A ausência da mãe provoca, portanto, uma divagação sobre um acontecimento corriqueiro, que leva o poeta a se lembrar de suas viagens, nas quais se entregara ao amor carnal. Amor que praticava "para sentir melhor que possuía" (p. 158) e que acabava convertendo em poesia.

O poeta, por alguns momentos, abandona os devaneios ao levantar os olhos e se perceber observado pelo calafate do prédio fronteiro, que come o seu caldo, um acontecimento imediato, relativo ao plano exterior da narração, construído a partir da percepção visual da personagem - reiterada a todo momento -, não mais de seu deslocamento, como nas ocorrências anteriores:

Levantou os olhos para a janela. No prédio fronteiro, viu o calafate sentado à mesa, que o observava amigavelmente por cima da escudela fumegante. Acenou-lhe de cabeça, e o outro fez com a mão um gesto largo, que terminou apontando o caldo numa oferta gentil. Correspondeu com um gesto como 
que de adeus e desviou os olhos. À varanda vieram encostar-se as duas crianças; não precisava de olhar para saber. (p. 158)

Há uma comunicação silenciosa entre o calafate e o poeta, estabelecida por meio de olhares e gestos, através da janela, quase como um espelhamento, uma vez que ambos se encontram sentados à mesa e respondem com gestos semelhantes; aquele de forma mais efusiva, e este de modo mais comedido. Camões logo desvia o olhar e, em seguida, percebe que duas crianças encostam-se à varanda. É a presença delas que faz com que ressurjam os devaneios: "Nunca gostara de crianças, nunca pensara em tomar estado para tê-las suas. Talvez por isso mesmo é que tanto ou tudo da sua poesia ficara como aqueles filhos que não quisemos ter, e que depois se despegam de nós adivinhando um desapego de que nos arrependemos” (p. 158). Por associação, isso o leva a pensar sobre o amor, que lhe "fora carne e espírito, tão carne, que nenhum espírito podia estar presente, e tão espírito, que nem toda a carne do mundo, usada dia e noite, chegava para contentá-lo” (p. 158), evidenciando a temática camoniana da coexistência do amor erótico e do amor espiritual. Entretanto, para ele, o amor carnal era sempre como na primeira vez, isto é, "uma surpresa, uma ignorância curiosa, um receio tímido, uma insegurança doce, um pasmo juvenil, uma alegria nova, um encantamento frenético" (p. 159). É interessante realçar a tentativa da personagem, por meio da voz do narrador, de caracterizar o amor carnal praticado pela primeira vez através da enumeração de substantivos abstratos sempre precedidos por um artigo indefinido e qualificados por adjetivos predominantemente positivos.

Em seguida, a personagem volta-se outra vez ao mundo exterior e percebe que as crianças não se encontram mais na varanda e que o calafate ainda está comendo, de modo que o plano exterior seja construído novamente a partir de sua visão: "Novamente ergueu os olhos para a varanda fronteira. As crianças não estavam lá, e o homem, curvado para a escudela, comia o seu caldo" (p. 159). A retomada do ambiente reitera a posição de Camões no espaço e desperta lembranças da conversa que tivera com o frade dominicano, naquele mesmo dia. A rememoração provoca reflexões acerca da Encarnação, cujo sentido o frade explicara com eloquência, mas que a ele, Camões, não precisava que explicassem, pois "Quem amara com a carne e com o pensamento como ele, quem escrevera do Amor como ele escrevera, e quem não gostara nunca de crianças, como ele, tinha da Encarnação uma experiência que o frade não tinha" (p. 159). A densidade metafísica de "sentir-se grávido de um poema" (p. 159) - condição sobre a qual o poeta parece não ter escolha - é tamanha, que gestação nenhuma pode compararse a essa, dado que 
o poeta que praticou o amor até à destruição da carne, e escreveu poemas até que o espírito acha pouco a poesia, esse, sim, esse sabe o que Encarnação seja. Apenas, porém, o sabe. Mas não viveu a Encarnação, foi a Encarnação quem o viveu a ele. E é este o grande mistério, não o outro. E é a grande diferença entre um deus que se encarna, e o homem em quem a Encarnação se representa. (p. 159)

A fim de exemplificar essa diferença, ele recorre ao mito de Anfitrião, homem em quem o deus Júpiter se encarnou, situação cômica em comparação com a experiência sublime do poeta, "em quem a Encarnação se representa". ${ }^{6}$ Nesse excerto, verificamos, portanto, a experiência metafísica da transfiguração do amor em poesia. Amor que se apresenta, alegoricamente, em dois níveis: como experiência e sensação e como criação e pensamento, assim como os planos narrativos e como a oposição bíblica entre Babel e Sião.

Os pensamentos acerca da Encarnação são interrompidos pelo rumor provocado pela chegada da mãe à casa, que prontamente inicia o relato dos acontecimentos do dia, em longos parágrafos de diálogo, em que o filho só toma a voz para corrigi-la e contrariá-la: "A porta rangeu, e os passinhos leves soaram atrás dele. A voz fininha e aguda começou a sua declamação desafinada” (p. 159). Até então, incitado pela ideia da conversão do amor em poesia, o poeta via "diante de si o palco iluminado, e as figuras declamando os versos" (p. 159). Apesar da presença dos elementos que poderiam constituir o plano exterior, pois com ele se relacionam, sobretudo por compreenderem o sentido da visão, a imagem que a personagem tem diante dos olhos pertence ao plano interior, em virtude de ser apenas mental, uma recriação, e não um acontecimento no mundo concreto. Portanto, os elementos relativos ao plano exterior aparecem em segunda ordem e, ao invés de provocarem pensamentos, acabam por interrompêlos, ao contrário do que ocorre anteriormente.

Em certo momento, durante seu "monólogo", a mãe percebe que Camões perdera-se outra vez em devaneios e pergunta: “Tu estás a dormir, tu não ouves o que eu digo?” (p. 163), o que confirma a preocupação do poeta, expressa no primeiro parágrafo do conto, de que não poderia se deixar distrair pelas palavras da mãe, porque elas provocariam a tão temida abertura do "poço", que de fato se realiza agora. A extensa fala antecipa o surgimento de versos já compostos e prenuncia a abertura do poço, que culminará na composição das redondilhas "Babel e Sião". Vale destacar, ainda, que é pelo discurso da mãe que se acentua o contraste entre o passado e o presente de Camões: antes, "um rapaz tão forte e tão bonito", "tão vaidoso" e de "passos tão firmes" (p. 163), que despertava a paixão das mulheres e a inveja nos homens; agora, um homem abandonado, doente e envelhecido.

${ }^{6}$ Para Ana Hatherly (1999), esse fragmento alude ao auto Anfitriões, escrito por Camões. 
Ao perceber a chegada da noite e constatar que não há fogo em casa, a mãe desce para buscá-lo, a fim de acender a candeia. O plano exterior novamente se constrói a partir da percepção visual da escuridão e do silêncio do ambiente, numa construção sinestésica: "Abriu o olhar às trevas e ao silêncio" (p. 163). O poeta é deixado em companhia das trevas, do silêncio e de seus devaneios, despertados pela conversa da mãe a respeito dos versos sobre os "Salmos del-rei David” que lhe foram encomendados por Rui Dias. No escuro, ele percebe o espaço ao seu redor, que vê "com a mesma certeza e a mesma minúcia com que vira as naus do Gama navegando no mar, lá em baixo, vistas do Empíreo, com que vira Vénus abraçada a Júpiter e chorando, com que vira o Adamastor sair da nuvem grossa, com que vira o Veloso correndo pelo monte abaixo" (p. 164), lembrando-se de episódios de sua epopeia. Interessa ressaltar a repetição anafórica - recorrente no conto - da estrutura "com que vira", de modo a enfatizar a força da imagem poética, o que sugere que a ficção lhe parece tão real quando a realidade.

Essa lembrança provoca o surgimento de outra, relativa a um acontecimento real: sua briga com Borges, a quem acutilara "Para que a vida lhe mudasse de rumo, para que ela tomasse um rumo de fatalidade, para que as Índias lhe fossem impostas pela sua estrela, para que a sua estrela existisse" (p. 164). Essa alusão à ideia de destino, sorte, fortuna por associação faz com que surjam, em prosa, versos de sua poesia lírica: "Erros meus, má fortuna, amor ardente, em minha perdição se conjuraram, os erros e a fortuna sobejaram, que para mim bastava amor somente" (p. 164), completando a referência a duas das mais importantes e conhecidas formas empregadas por Camões em medida nova: a epopeia e o soneto de modelo italiano. O fragmento do poema lírico aborda temas clássicos da poesia camoniana: o amor, a perdição e a desventura.

O poeta então dedica-se a pensar sobre a criação poética, a perdição e o amor. Para falar da criação poética e da poesia, a personagem se utiliza de paradoxos, como se não conseguisse expressar a transcendentalidade do fazer poético de outra maneira, em busca de um entendimento talvez inalcançável: "Como a poesia é falsa e verdadeira. Como ela diz não dizendo, e é não dizendo que diz. Como da nossa alma não sabemos nada antes de escrevê-la, e como não é dela que sabemos depois de ter escrito" (p. 164). Além disso, ele se apropria de mitos para esclarecer abstrações, torná-las mais assimiláveis. Desta vez, acerca da perdição: “A perdição procura-se, como um homem se despe para banhar-se no mar, a modos que Leandro atravessando o Helesponto" (p. 164). A perdição é, pois, comparada aos esforços de Leandro (para quem o amor carnal foi, de fato, a perdição), que, todas as noites, atravessava o estreito de Helesponto a nado para encontrar Hero, sua amada. Enquanto a perdição atrela-se ao mundo das sensações, o amor é abordado sob uma perspectiva metafísica, já que se relaciona 
ao espiritual, pois é ideia, essência que transcende o tempo e o espaço: "E se esse amor não fosse mais do que uma imagem, uma essência última da sua própria vida?” (p. 164), reflexões que encerram uma concepção neoplatônica do amor.

O poço, fonte da criação poética, como que provocado pela elevação da poesia, abrese, e, no momento em que "as pequeninas formas flutuantes" (p. 164), pedaços luminosos de versos, começam a emergir, a mãe retorna à casa, afugentando momentaneamente as ideias do poeta. A quebra desse fluxo decorre do rangido gerado pela abertura da porta, pela claridade que adentra o recinto e pelos "passinhos leves" da mãe, indicando que as divagações (isto é, o plano interior da narração) são interrompidas pelas percepções auditiva e visual e reiterando a ideia de que são a escuridão e o silêncio que incentivam seus devaneios. Os objetos do espaço, antes rememorados, agora se mostram fisicamente visíveis para Camões. A mãe torna a mencionar a encomenda de Rui Dias e, diante do silêncio do filho, se vai deitar. Mais uma vez, o poeta volta-se ao mundo exterior e fica a contemplar "as chispinhas delicadas" da candeia (p. 165). Considerando o que a mãe dissera, põe-se a pensar no que diria ao criado que viesse buscar a encomenda, quando, subitamente, seus pensamentos são interrompidos. As redondilhas começam a ser estruturadas: "Seriam 365 versos, tantos quantos os dias do ano, como uma via sacra da vida, 73 quintilhas como...” (p. 166). Cessam os devaneios acerca dos acontecimentos da realidade concreta, e, finalmente, após a abertura do poço, o processo de composição de "Sobre os rios que vão" tem início.

Eufórico, voltando-se ao planto exterior, o poeta levanta-se, impelido por uma ânsia que lhe corta a respiração. Quando em posse de tinta e papel, ajoelha-se, incomodado pelas dores, "sintomas de um verdadeiro nascimento" (HATHERLY, 1999, p. 30). Sentindo na pele o efeito do calor poético que o assalta, pois “Já as palavras tumultuavam nele, confundidas com as outras, inúteis e mortas, da tradução que tentara" (p. 167), debruça-se à mesa. Tomado novamente pela alegria de fazer versos, "os olhos ardiam-lhe e era de lágrimas" (p. 166), torna ao plano interior, devaneando a respeito do abandono da própria poesia, mas já certo de sua grandeza como poeta, capaz de transformar "em poesia tudo o que tocava, mesmo a miséria, mesmo a amargura, mesmo o abandono da poesia" (p. 166). Retorna, então, aos acontecimentos imediatos, da realidade concreta. Apesar do tremor que o domina, mantém a mão firme e começa a escrever: "Sobre os rios que vão de Babilónia a Sião assentado me achei...". Desesperado, risca e recomeça: "Sobre os rios que vão por Babilónia me achei onde sentado chorei as lembranças de Sião e quanto nela passei... E ficou escrevendo pela noite adiante" (p. 166). Os parágrafos finais do conto representam, portanto, a conjunção dos planos, uma vez que os versos são elaborados no plano interior e materializados no plano exterior, 


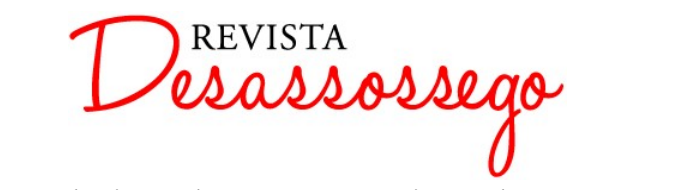

DESASSOSSEGO 21 | DEZ/2019 | ISSN 2175-3180

DOI: http://dx.doi.org/10.11606/issn.2175-3180.v11i21p23-33

culminando na composição do poema.

Ainda vale notar que, nas redondilhas de Camões, Babilônia refere-se ao mal presente, onde o desterrado chora as lembranças de Sião e o tempo passado, numa "oposição entre o Mal (lugar de perdição) e o Bem (lugar de salvação)", conforme aponta Sena (1980, p. 113) no ensaio "Babel e Sião". É interessante recordar que o poema "serve de ponte de passagem entre o primeiro e o segundo Camões lírico" e que "constitui peça indispensável para a compreensão do Poeta, além de ser um dos momentos mais altos de sua inspiração poética”, porquanto nela "Camões plasma a sua íntima e solitária luta para ascender, metafisicamente falando: a grande tragédia do Homem, de que o Poeta é apenas a expressão particular, está numa saudade mortal do 'divino aposento', o plano das essências" (MOISÉS, s.d., p. 25). Embora seja inspirado no salmo 136, o poema apresenta também experiência de Camões como poeta desterrado na própria pátria.

Da mesma forma, o conto de Jorge de Sena nos fornece, nas palavras de Ana Hatherly (1999, p. 26), "um quadro de emoções ligadas ao processo criativo de um poema, sim, mas também o retrato de um poeta que sofre um terrível isolamento e só encontra alívio na criação da sua obra". Na narrativa, observamos a presença de dois grandes blocos, que são o diálogo entre as personagens (em que são inseridas grande parte das informações biográficas sobre Camões) e a narração propriamente dita, sendo que esta se constitui por dois planos. O plano exterior é permeado por sensações diversas, sempre atreladas ao tato, à visão e à audição, e se relaciona à realidade física do poeta e aos acontecimentos presentes, enquanto o plano interior é composto por lembranças e devaneios e se relaciona ao passado. Importa lembrar que os elementos referentes ao primeiro plano ora deflagram, ora interrompem as divagações que compõem o segundo. Da articulação dos planos, surge a imagem do processo de criação poética, com o entrelaçamento de motivos recorrentes e versos inteiros da lírica camoniana.

Diante disso, percebemos que o conto se estrutura sobre as antíteses "viver e lembrar" e "sentir e pensar" e que há, ainda, uma cisão clara entre "agora" e "antes": a observação do mundo concreto, no conto, corresponderia a Babel, ao passo que a contemplação do mundo psicológico corresponderia a Sião. É o contraste entre a vida e a obra do poeta, entre a sua degradação presente e a sua glória passada, assim como no poema de Camões, situação que Jorge de Sena recriou ficcionalmente em "Super Flumina Babylonis", de modo que o conto espelhasse as redondilhas.

\section{REFERÊNCIAS}

HATHERLY, Ana. O nascimento de um poema: Historicismo e realismo imaginoso em Super 
Flumina Babylonis de Jorge de Sena. In: SANTOS, Gilda (org.). Jorge de Sena em rotas entrecruzadas. Lisboa: Edições Cosmos, 1999, p. 21-32.

MOISÉS, Massaud. Prefácio. In: CAMÕES, Luís de. Lírica. Seleção, prefácio e notas de Massaud Moisés. São Paulo: Cultrix, s.d., p. 9-37.

RIBEIRO, Carla. “'Super Flumina Babylonis': Camões e Sena nas margens do mesmo rio". Revista Crioula, n. 3, mai. 2008. Disponível em: https://doi.org/10.11606/issn.19817169.crioula.2008.54011. Acesso em: 19 out. 2015.

SENA, Jorge de. Babel e Sião. In: SENA, Jorge de. Trinta anos de Camões. Vol. I. Lisboa: Edições 70, 1980, p. 113-131.

SENA, Jorge de. Camões: o poeta lírico. In: SENA, Jorge de. Trinta anos de Camões. Vol. I. Lisboa: Edições 70, 1980, p. 287-294.

SENA, Jorge de. Prefácio a Novas andanças do demónio (1966). In: SENA, Jorge de. Antigas e novas andanças do demónio. 2. ed. Lisboa: Edições 70, 1981, p. 219-224.

SENA, Jorge de. Super Flumina Babylonis. In: SENA, Jorge de. Antigas e novas andanças do demónio. 2. ed. Lisboa: Edições 70, 1981, p. 155-166.

SILVA, Teresa Cristina Cerdeira da. Dos rios que vão de Camões a Sena. In: SANTOS, Gilda (org.). Jorge de Sena em rotas entrecruzadas. Lisboa: Edições Cosmos, 1999, p. 303-310. 